\title{
Debridman, antibiyotik ve implantların korunması (DAIR prosedürü)
}

\author{
Debridement, antibiotics, implant retention (DAIR procedure)
}

\author{
Murat Bozkurt ${ }^{1}$, Safa Gürsoy ${ }^{2}$
}

\begin{abstract}
${ }^{1}$ Yıldırım Beyazıt Üniversitesi Atatürk Eğitim ve Araştırma Hastanesi, Ortopedi ve Travmatoloji Kliniği, Ankara ${ }^{2}$ Yıldırım Beyazıt Üniversitesi Yenimahalle Eğitim ve Araştırma Hastanesi, Ortopedi ve Travmatoloji Kliniği, Ankara
\end{abstract}

Periprostetik eklem enfeksiyonları, revizyon cerrahilerinin en sık nedenlerinden biri olan, zorlu bir komplikasyondur. Periprostetik eklem enfeksiyonlarının tedavisinde; konservatif yaklaşımlardan, iki seanslı revizyona kadar farklı tedavi yaklaşımları kullanılmaktadır. Uygun tedavi yaklaşımının belirlenmesinde; semptomların süresi, ortaya çıkış zamanı, hastanın durumu gibi birçok faktör göz önünde bulundurulmalıdır. Erken dönem enfeksiyonların tedavisinde, uygun hasta grubunda "Debridman, Antibiyotik ve İmplantların Korunması (DAIR Prosedürü)" yöntemi ile literatürde başarılı sonuçlar bildirilmiştir.

Anahtar sözcükler: artroplasti; periprostetik eklem enfeksiyonları; debridman; DAIR prosedürü
Periprosthetic joint infection which is one of the most common causes of revision surgery is a challenging complication. In the treatment of periprosthetic joint infections, from conservative approach to two-stage revision, different therapeutic approaches are available. several factors should be considered while determining the appropriate treatment option, such as duration of symptoms, appearance time, patient's condition, etc. For the treatment of early infections in appropriate patients by the method of "Debridement, Antibiotics, Implant Retention (DAIR Procedure)", successful results were observed in the literature.

Key words: arthroplasty; periprosthetic joint infections; debridement; DAIR procedure
T otal eklem artroplastisi, eklem artrozu olan hastalarda yaşam kalitesini arttıran ve eklem fonksiyonlarını geri kazandıran, güvenilir ve etkili bir yöntemdir. Total eklem artroplastileri sonrası enfeksiyon, en ciddi komplikasyonlardan biri olarak karşımıza çıkmaktadır. Doğru cerrahi yaklaşımlar, uygun antibiyotik profilaksileri ve diğer tüm önlemlere rağmen, periprostetik eklem enfeksiyonları (PPE); revizyon nedenleri içinde diz artroplastisinde birinci, kalça artroplastisinde ise en sık üçüncü neden olarak karşımıza çıkan önemli bir problemdir. ${ }^{[1-3]} \mathrm{PPE}$, primer diz ve kalça artroplastisi sonrası \%1-2 oranında görülmektedir. ${ }^{[4,5]}$ Periprostetik enfeksiyonların maliyet açısından ortaya çıkardığı yük ise giderek artmaktadır. Amerika Birleşik Devletleri'nde, hastane ve cerrah açısından maliyet 2001 yılında $\$ 320$ milyon iken, bu rakam 2009 yılında $\$ 566$ milyon olarak hesaplanmıştır. 2020 yılı için yapılan projeksiyonda, bu maliyetin $\$ 1,62$ milyara ulaşması öngörülmektedir. ${ }^{[6]}$ Periprostetik enfeksiyonların erken tanı ve tedavisi, enfeksiyonun kronik hale gelmemesi, tekrarlayan cerrahilerin, artan maliyetlerin, yüksek mortalite ve morbiditenin engellenmesi açısından önemlidir. ${ }^{[7,8]}$

Artroplasti uygulamalarının yaygınlaştı̆̆ı yıllardan bu yana, derin periprostetik enfeksiyonların tedavisindeki en uygun yaklaşım konusundaki tartışmalar sürmektedir. ${ }^{[9,10]}$ PPE'nin yönetiminde birden çok tedavi alternatifi bulunmaktadır. Bu tedavi şeçenekleri;

- antibiyotik tedavisi,

- "Debridman, Antibiyotik ve İmplantların

Korunması" olarak bilinen DAIR prosedürü,

- tek seans revizyon,

- iki seans revizyon,

- artrodez ve

- ampütasyon olarak sıralanabilir.

Enfekte komponentlerin çıkarılmasının ardından ve protezsiz, antibiyotik sement ile hazırlanan bir spacer

- Illetişim adresi: Prof. Dr. Murat Bozkurt, Yıldııı Beyazıt Üniversitesi Atatürk Eğitim ve Araştırma Hastanesi, Ortopedi ve Travmatoloji Kliniği, Bilkent, Ankara Tel: 0312 - 2912525 e-posta: nmbozkurt@gmail.com

- Geliș tarihi: 1 Mart $2016 \quad$ Kabul tarihi: 1 Mart 2016 


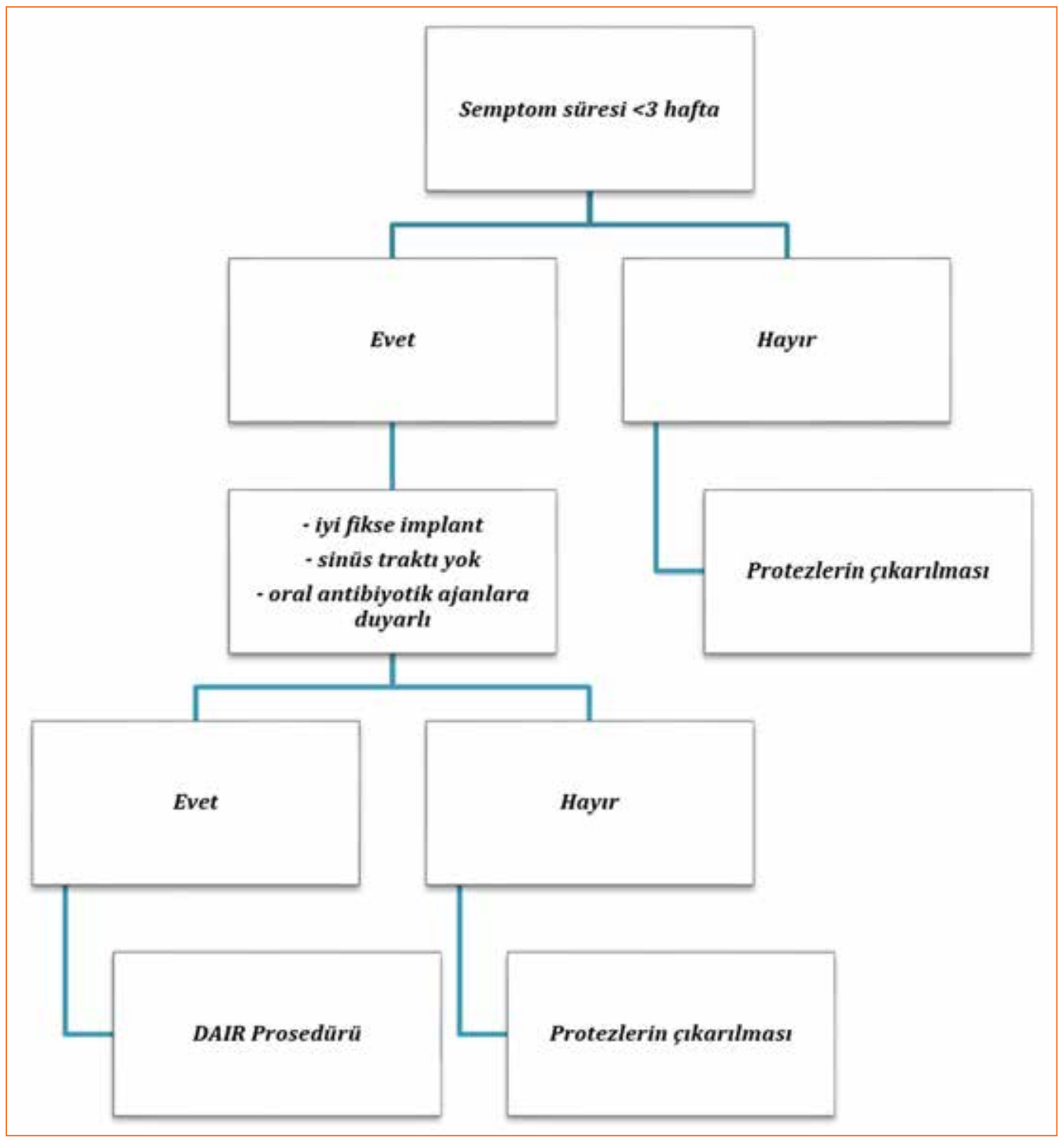

Şekil 1. Periprostetik enfeksiyonlarda DAIR prosedürü için tedavi algoritması. ${ }^{[16]}$

ile takip edilen bir dönemin izlediği ve sonrasında revizyon komponentlerin re-implante edildiği iki seans revizyon cerrahisi, birçok PPE olgusunun tedavisinde altın standart olarak kabul görmektedir. ${ }^{[9]}$ iki seans revizyon cerrahisinin, özellikle implantsız geçen ara dönemde meydana gelen doku değişikliklerine, reimplantasyon sonrası önemli fonksiyonel eksikliklere neden olabilme ve aynı zamanda hastalar tarafindan tolere edilmesi zor olan yüksek mortalite ve morbiditeye sahip olma gibi bazı dezavantajları vardır. ${ }^{[9-11]}$ Bu bilgiler ışığında, özellikle Avrupa'daki bazı merkezlerde, uygun hastalarda tek seans revizyon cerrahisine olan ilgi gittikçe artmaktadır. ${ }^{[12,13]}$ Tek seans revizyonun, daha az mortalite, morbitide ve fonksiyonel gerileme ile birlikte, tekrarlayan hastaneye yatışları azalttığı ve önemli oranda maliyetleri düşürdüğü savunulmaktadır. ${ }^{[12-15]}$

Uygun tedavi rejiminin belirlenmesinde; enfeksiyonun yaygınlığı, kronikliği, enfektif organizmanın virülansı, çevre yumuşak dokunun durumu ve hastanın fizyolojik durumu gibi birçok parametre göz önünde bulundurulmalıdır. Aynı zamanda, tedavi alternatiflerinin belirlemesinde bazı klinik algoritmalar kullanılmaktadır (Şekil 1).

Tüm bu faktörler göz önünde bulundurulduğun$\mathrm{da}$, protez enfeksiyonlarında DAIR prosedürü olarak 
Tablo 1. Tsukayama ve arkadaşlarının yapmış

Erken postoperatif enfeksiyon Operasyon sonrası bir ay içinde gelişen enfeksiyon.

Geç kronik enfeksiyon

Operasyondan bir ay sonrası gelişen, subakut ve sinsi klinik semptomlarının bulunduğu enfeksiyon.

Akut hematojen enfeksiyon

Fonksiyonu iyi olan bir eklemde, akut semptomların bulunduğu enfeksiyon.

Tablo 2. Zimmerli ve arkadaşlarının yapmış oldukları PPE sınıflaması

$\begin{array}{ll}\text { Erken enfeksiyon } & \begin{array}{l}\text { Eklem replasmanı yapıldıktan } \\ \text { sonraki ilk üç ayda. }\end{array} \\ \text { Gecikmiş enfeksiyon } & \begin{array}{l}\text { Eklem replasmanından sonraki } \\ \text { 3-24 ay içinde. }\end{array}\end{array}$

Geç enfeksiyon Eklem replasmanından 24 ay sonra. oldukları PPE sınıflaması

\section{DAIR PROSEDÜRÜNÜN ENDIKASYONLARI}

- Kısa semptom süresi olan hastalarda,

- iyi fikse ve fonksiyonel implantı olan hastalarda ve

- mikrobiyolojik olarak iyi karakterize edilmiş, duyarlı organizma gösterilmiş hastalarda, DAIR prosedürünün uygulanması önerilmektedir. [19]

Parvizi ve arkadaşlarının yapmış oldukları PPE konsensus çalışmasında, DAIR prosedürünün, primer artroplastinin ardından geçen üç ay aylık dönem içerisinde ortaya çıkan ve semptom süresi üç haftayı geçmemiş olgularda uygulanabileceği görüşü sunulmaktadır. Yine aynı çalışmada, geç hematojen enfeksiyonlarda bu tekniğin, yine semptomların başlamasının ardından ilk üç hafta içerisinde uygulanması gerektiği savunulmaktadır. ${ }^{[20]}$

\section{DAIR PROSEDÜRÜNÜN KONTRAENDIKASYONLARI}

Protezlerin korunarak sadece modüler komponentlerin değiştirildiği “DAIR" prosedürü, birden çok eklem artroplastisi olan ve/veya semptomu bir aydan uzun süredir devam eden hastalarda kontrendikedir. ${ }^{[21,22]}$

Yine konsensuslara göre, cildin kapanmasında sorunlara sahip, sinus traktı bulunan ve gevşemiş proteze sahip olgular, DAIR prosedürü için kesin kontrendike olarak kabul edilmektedir. ${ }^{[20]}$

\section{CERRAHI TEKNIK}

DAIR prosedüründe, aşağıda yer alan standart cerrahi yaklaşım aşamaları titizlikle uygulanmalıdır (Şekil 2).

- Ameliyat öncesinde, hasta için uygun endikasyon yukarıda yer alan parametreler doğrultusunda optimize edilmelidir.

- Ekleme, mümkün ise, eski insizyondan ulaşılır. Uygun görüntülemenin ardından, debridman total sinoviyektomiyi de içerecek şekilde gerçekleştirilir.

Periprostetik enfeksiyonları, özellikle enfeksiyonun ortaya çıkış zamanına göre bazı alt gruplara ayırmak, farklı tedavi yaklaşımlarının belirlenmesi açısından oldukça önemlidir. PPE, primer cerrahinin ardından ortaya çıkan zamana göre üç grupta sınıflandırılabilir (Tablo 1). ${ }^{17]}$ Zimmerli ve ark. tarafından yapılmış, erken enfeksiyonların üç aydan önce, gecikmiş enfeksiyonların 3-24 ay arası ve geç enfeksiyonların ise eklem replasmanından 24 ay sonra olarak tanımlandığı benzer bir sınıflama sistemi de mevcuttur (Tablo 2). ${ }^{18]}$
- En az üç, en fazla altı örnek olmak üzere, kültürler için, sinoviyum, kapsül ve arayüzleri de içerecek doku ve sıvı örnekleri alınır.

- Altı-dokuz litre arasında salin ile, eklemin irrigasyonu yapılır. İrrigasyon sıvısına farklı antiseptik solüsyonların eklenmesi konusundaki tecrübeler literatürde yer almakla birlikte, bu konuda net bir konsensus mevcut değildir.

- Tüm modüler komponentler, mümkün ise çıkarılmalı ve değiştirilmelidir. 

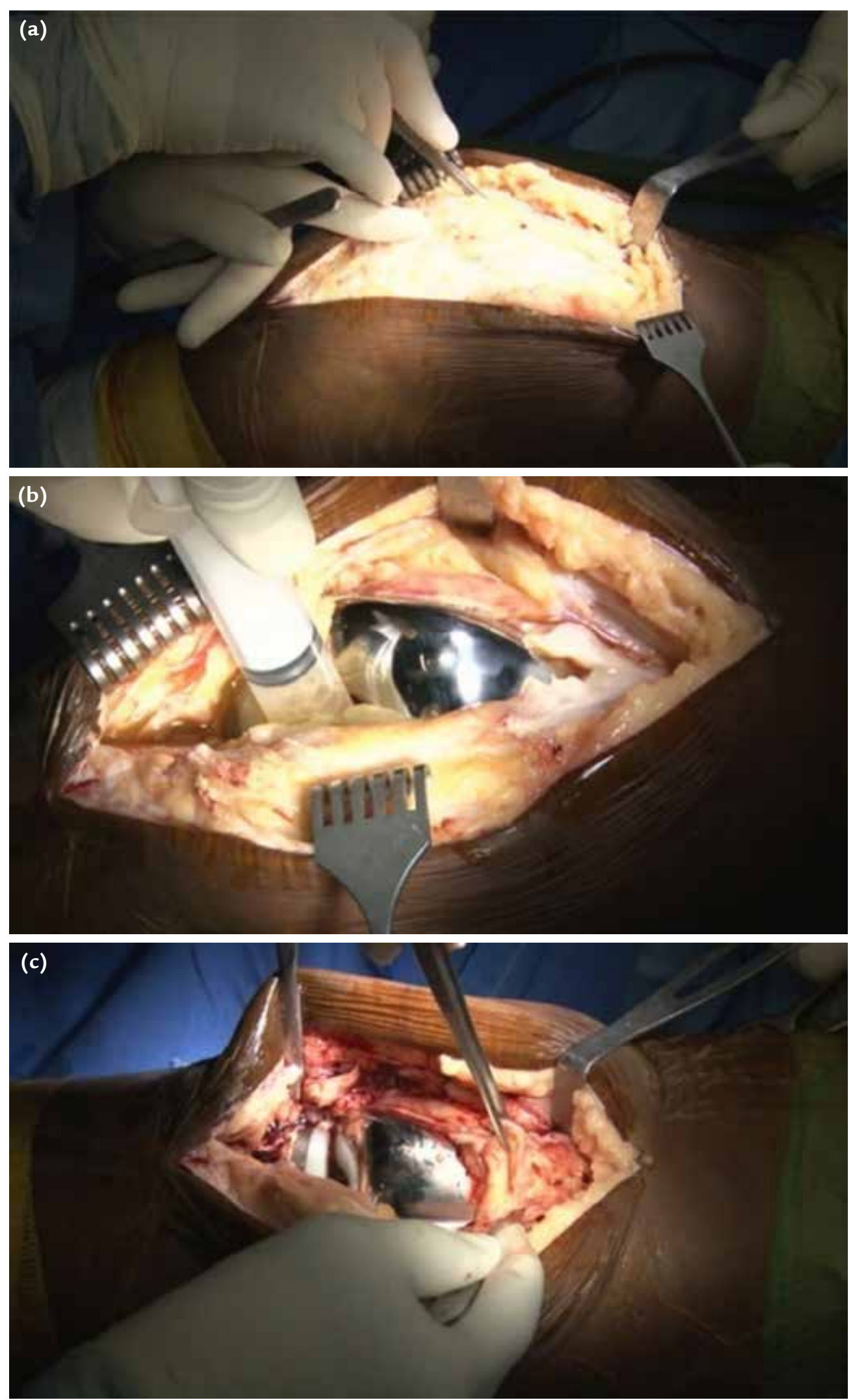

Şekil 2. a-c. DAIR Prosedürünün cerrahi aşamaları; eski insizyon ve mediyal parapatellar yaklaşım ile ekleme ulaşııması (a), sıvı ve doku örneklerinin alınması (b), total sinoviyektomiyi içeren geniş debridman (c). 


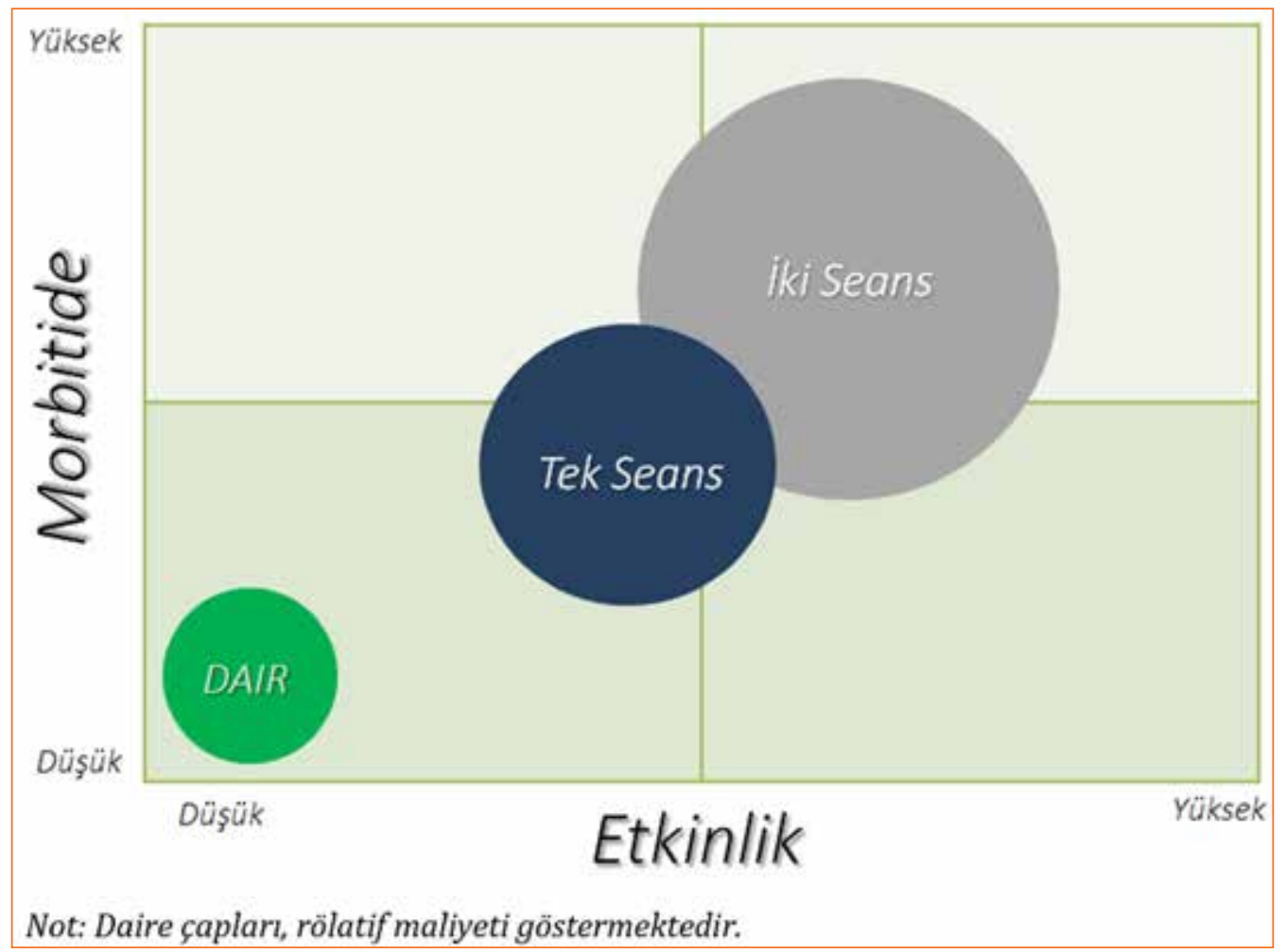

Şekil 3. Erken dönem periprostetik enfeksiyonlarda klinik karar verme süreci. Cerrahi teknikler arasındaki etkinlik, morbitide ve rölatif maliyet ilişkileri.

Debridmanın artroskopik olarak da uygulanabileceği yönünde yayınlar mevcut olsa da, özellikle Staphylococcus aureus enfeksiyonlarında ve daha önce revize edilmiş hastalarda, artroskopik debridmanda başarısızlık oranları daha yüksektir. ${ }^{[23]}$ Ayrıca, gerçekleştirilen konsensus çalışmasında, artroskopinin DAIR prosedürü içerisinde rolü olmadığı belirtilmektedir. ${ }^{[20]}$

\section{DAIR PROSEDÜRÜ SONRASI ANTIBIYYTERAPI}

Etken ve kliniğe göre farklı algoritmalar ve antibiyotik kombinasyonları mevcuttur. Genel olarak izlenen yöntemle, 2-6 hafta süre ile intravenöz tedavi ve sonrasında uzatılmış tedavi veya outpatient parenteral antimicrobial therapy (OPAT) ile kür sağlanabilmektedir. ${ }^{[16]}$

DAIR prosedürü sırasında, teorik olarak, toksik serum antibiyotik seviyeleri oluşturmadan eklem içi yüksek antibiyotik konsantrasyonu elde etmek için, antibiyotikli boncuk veya spançların kullanımı konusunda görüşler mevcuttur. Hatta, boncukların spanç formlarına göre daha uzun antibiyotik salınımı sağladığını gösteren çalışmalar yapılmıştır. ${ }^{[24]}$ Ancak yine, yapılan çalışmalarda, bu yapıların bakterilerin bağlanabileceği bir yabancı cisim davranışı gösterebileceği de savunulmaktadır. ${ }^{[25]}$ Konsensus çalışmasında ise; devamlı, intra-artiküler antibiyotik uygulamasının DAIR prosedüründe yeri olmadığı belirtilmektedir.

\section{KLINIK KARAR VERME VE SONUÇLAR}

Erken dönem periprostetik eklem enfeksiyonlarının tedavisinin belirlenmesinde, klinik karar verme sürecindeki amaç, en uygun ilk tedavi yöntemini belirleyebilmektir. Uygun tedavi belirlenirken, minimum maliyet ve morbitidenin yanında, maksimum etkinlik ve yarar sağlanması esastır. Şekil 3'te, klinik verilerinin değerlendirilmesi sonrasında, periprostetik eklem enfeksiyonlarında yaygın olarak uygulanan üç yöntem olan DAIR prosedürü, tek seans ve iki seans tedaviler arasındaki etkinlik, morbidite ve rölatif maliyet ilişkileri gösterilmektedir.

DAIR prosedürü erken dönem periprostetik enfeksiyonlarda ilk seçenek gibi görünse de, klinik karar verme süreçlerinde, tedavi etkinliği, maliyet ve hastaya ait faktörler göz önünde bulundurulmalıdır. 
DAIR prosedürünün literatürde $\% 14^{[26]}$ ila $\% 100^{[27]}$ arasında değişen başarı oranları mevcuttur. Yine yapılan çalışmalarda; stabil implantları olan, kısa semptom süresine sahip ve sağlıklı çevre yumuşak dokusunun mevcut olduğu uygun hasta popülasyonunda \%70'in üzerinde başarı oranları elde edilebileceği gösterilmiştir. ${ }^{[16,23,28-30]}$

Kronik enfeksiyon varlığında, implantların korunmasının başarısı oldukça düşüktür. Semptomların başlaması ile debridmanın uygulanması arasında geçen sürenin, klinik sonuçları direkt olarak etkilediği gösterilmiştir. Brandt ve ark. ${ }^{[31]}$ gerçekleştirmiş oldukları çalışmada, semptomların başlamasının ardından ilk iki gün içerisinde uygulanan debridmanda başarı oranını $\% 56$, ikinci günden sonra gerçekleştirilen tedavide başarı oranını ise \%13 olarak tespit etmişlerdir. Yine benzer bir çalışmada, semptomların başlamasının iki hafta sonrasında uygulanan tedavide, 42 olguda başarı elde edilememiştir. ${ }^{[26]}$

\section{KAYNAKLAR}

1. Bozic KJ, Kurtz SM, Lau E, Ong K, Chiu V, Vail TP, Rubash HE, Berry DJ. The epidemiology of revision total knee arthroplasty in the United States. Clin Orthop Relat Res 2010;468(1):4551. Crossref

2. Bozic KJ, Kurtz SM, Lau E, Ong K, Vail TP, Berry DJ. The epidemiology of revision total hip arthroplasty in the United States. J Bone Joint Surg Am 2009;91(1):128-33. Crossref

3. Clohisy JC, Calvert G, Tull F, McDonald D, Maloney WJ. Reasons for revision hip surgery: a retrospective review. Clin Orthop Relat Res 2004;(429):188-92.

4. Trampuz A, Zimmerli W. Prosthetic joint infections: update in diagnosis and treatment. Swiss Med Wkly 2005;135(17-18):243-51.

5. Del Pozo J L, Patel R. Clinical practice. Infection associated with prosthetic joints. N Engl J Med 2009;361(8):787-94. Crossref

6. Kurtz SM, Lau E, Watson H, Schmier JK, Parvizi J. Economic burden of periprosthetic joint infection in the United States. J Arthroplasty 2012;27(8 Suppl):61-5.e1. Crossref

7. Barrack RL, Burnett RS, Sharkey P, Parvizi J. Diagnosing an infection: an unsolved problem. Orthopedics 2007;30(9):777-8.

8. Martí-Valls J, Alonso J, Lamarca R, Pinto JL, Auleda J, Girvent R, López E, Miralles R, Ramón R, Saló JM. Effectiveness and cost of total hip replacement in seven hospitals in Catalonia, Spain. Med Clin (Barc)2000;114 Suppl 2:34-9.

9. Matthews PC, Berendt AR, McNally MA, Byren I. Diagnosis and management of prosthetic joint infection. BMJ 2009;338:b1773. Crossref

10. Sanzen L, Carlsson AS, Josefsson G, Lindberg LT. Revision operations on infected total hip arthroplasties. Twoto nine-year follow-up study. Clin Orthop Relat Res 1988;(229):165-72.

11. Langlais F. Can we improve the results of revision arthroplasty for infected total hip replacement? J Bone Joint Surg $\mathrm{Br}$ 2003;85(5):637-40.
12. Gehrke T, Kendoff D. Peri-prosthetic hip infections: in favour of one-stage. Hip Int 2012;22 Suppl 8:S40-45. Crossref

13. Klouche S, Leonard P, Zeller V, Lhotellier L, GraffW, Leclerc P, Mamoudy P, Sariali E. Infected total hip arthroplasty revision: one or two-stage procedure? Orthop Traumatol Surg Res 2012;98(2):144-50. Crossref

14. Klouche S, Sariali E, Mamoudy P. Total hip arthroplasty revision due to infection: a cost analysis approach. Orthop Traumatol Surg Res 2010;96(2):124-32. Crossref

15. Merollini KM, Crawford RW, Graves N. Surgical treatment approaches and reimbursement costs of surgical site infections post hip arthroplasty in Australia: a retrospective analysis. BMC Health Serv Res 2013;13:91. Crossref

16. Osmon DR, Berbari EF, Berendt AR, Lew D, Zimmerli W, Steckelberg JM, Rao N, Hanssen A, Wilson WR; Infectious Diseases Society of America. Executive summary: diagnosis and management of prosthetic joint infection: clinical practice guidelines by the Infectious Diseases Society of America. Clin Infect Dis 2013;56(1):1-10. Crossref

17. Tsukayama DT, Estrada R, Gustilo RB. Infection after total hip arthroplasty. A study of the treatment of one hundred and six infections. J Bone Joint Surg Am 1996;78(4):512-23.

18. Zimmerli W, Trampuz A, Ochsner PE. Prosthetic-joint infections. N Engl J Med 2004;351(16):1645-54.

19. Marculescu CE, Berbari EF, Hanssen AD, Steckelberg JM, Harmsen SW, Mandrekar JN, Osmon DR. Outcome of prosthetic joint infections treated with debridement and retention of components. Clin Infect Dis 2006;42(4):471-8.

20. Parvizi J, Gehrke T, Chen AF. Proceedings of the International Consensus on Periprosthetic Joint Infection. Bone Joint J 2013;95-B(11):1450-2. Crossref

21. Parvizi J, Zmistowski B, Adeli B. Periprosthetic joint infection: treatment options. Orthopedics 2010;33(9):659. Crossref

22. Jafari SM, Casper DS, Restrepo C, Zmistowski B, Parvizi J, Sharkey PF. Periprosthetic joint infection: are patients with multiple prosthetic joints at risk? J Arthroplasty 2012;27(6):877-80. Crossref

23. Byren I, Bejon P, Atkins BL, Angus B, Masters S, McLardySmith $P$, Gundle R, Berendt $A$. One hundred and twelve infected arthroplasties treated with 'DAIR'(debridement, antibiotics and implant retention): antibiotic duration and outcome. J Antimicrob Chemother 2009;63(6):1264-71. Crossref

24. Diefenbeck M, Mückley T, Hofmann GO. Prophylaxis and treatment of implant-related infections by local application of antibiotics. Injury 2006;37 Suppl 2:S95-104.

25. Barth RE, Vogely HC, Hoepelman Al, Peters EJ. 'To bead or not to bead?' Treatment of osteomyelitis and prosthetic joint-associated infections with gentamicin bead chains. Int J Antimicrob Agents 2011;38(5):371-5. Crossref

26. Crockarell JR, Hanssen AD, Osmon DR, Morrey BF. Treatment of infection with debridement and retention of the components following hip arthroplasty. J Bone Joint Surg Am 1998;80(9):1306-13.

27. Zimmerli W, Widmer AF, Blatter M, Frei R, Ochsner PE. Role of rifampin for treatment of orthopedic implantrelated staphylococcal infections: a randomized controlled trial. Foreign-Body Infection (FBI) Study Group. JAMA 1998;279(19):1537-41.

28. Soriano A, Garcia S, Bori G, Almela M, Gallart X, Macule F, Sierra J, Martinez JA, Suso S, Mensa J. Treatment of acute post-surgical infection of joint arthroplasty. Clin Microbiol Infect 2006;12(9):930-3. 
29. Vilchez F, Martinez-Pastor JC, Garcia-Ramiro S, Bori G, Maculé F, Sierra J, Font L, Mensa J, Soriano A. Outcome and predictors of treatment failure in early post-surgical prosthetic joint infections due to Staphylococcus aureus treated with debridement. Clin Microbiol Infect 2011;17(3):439-44. Crossref

30. Sukeik M, Patel S, Haddad FS. Aggressive early debridément for treatment of acutely infected cemented total hip arthroplasty. Clin Orthop Relat Res 2012;470(11):3164-70. Crossref
31. Brandt CM, Sistrunk WW, Duffy MC, Hanssen AD, Steckelberg JM, Ilstrup DM, Osmon DR. Staphylococcus aureus prosthetic joint infection treated with debridement and prosthesis retention. Clin Infect Dis 1997;24(5):914-9. 